\title{
BTEXs in Indoor and Outdoor Air Samples: Source Apportionment and Health Risk Assessment of Benzene
}

\author{
Haris Hafizal Abd Hamid ${ }^{1}$, Nor Sakinah Jumah ${ }^{2}$, Mohd Talib Latif ${ }^{1}$, Narayanan Kannan ${ }^{3 *}$ \\ ${ }^{1}$ Institute for Environment and Development (LESTARI), Universiti Kebangsaan Malaysia, 43600 UKM, Bangi, \\ Selangor, Malaysia \\ ${ }^{2}$ Faculty of Environmental Studies, Universiti Putra Malaysia (UPM), 43400 Serdang, Selangor, Malaysia \\ ${ }^{3}$ Research and Enterprise, Taylor's University, Jalan Taylor's, Selangor Darul Ehsan, Malaysia
}

*Corresponding Author: Narayanan Kannan, Research and Enterprise, Taylor's University (Lakeside Campus), No. 1, Jalan Taylor's, 47500, Subang Jaya, Selangor Darul Ehsan, Malaysia, Tel: +60143385307; E-mail: Kannan.Narayanan@taylors.edu.my

Received: 23 June 2017; Accepted: 07 July 2017; Published: 17 July 2017

\begin{abstract}
Level of benzene, toluene, ethyl benzene, m,p-xylene and o-xylene (BTEXs) was measured in several indoor and outdoor air samples. Five indoor air samples were from motor vehicle workshops and three samples were from gasoline filling stations and the rest were ambient air samples. They were collected using a 1L Tedlar® bag. BTEX analysis was performed with Thermal Desorption (TD) - Gas Chromatography Mass Spectrometer (GCMS). The concentration of $\Sigma$ BTEXs in indoor (ID1 to ID5) were 864.29, 115.32, 655.79, 72.99, $96.05 \mu \mathrm{g} / \mathrm{m}^{3}$ respectively. $\Sigma$ BTEXs in outdoor (OD1 to OD6) samples were, 367.45, 85.12, 50.29, 159.94, 46.02, $68.57 \mu \mathrm{g} / \mathrm{m}^{3}$ respectively. Calculated LADD value in indoor and outdoor air samples ranged in the scale of $0.27-3.42$ and $0.16-1.88 \mu \mathrm{g} / \mathrm{kg} / \mathrm{d}$ respectively. Concentrations of all indoor and outdoor samples surpassed the cancer risk (CR) limit for benzene but were below HQ $(<1)$ for non-cancer risk impact. In conclusion, areas within petroleum stations and motor vehicles workshops may pose hazardous cancer risk and non-cancer risk through BTEXs exposure to workers and nonworkers.
\end{abstract}

Keywords: Benzene; Toluene; Ethyl benzene; Xylene; BTEX; Air pollution; Source identification; Risk evaluation; Malaysia; Developing country 


\section{Introduction}

BTEX refers to Benzene, Toluene, Ethyl benzene and three isomers of Xylene and they are referred by World Health Organization (WHO) as hazardous air pollutants (HAPs) [1]. Humans who are exposed to BTEX for a long period of time have high risk to chronic disease, such as cancer [2]. For example, WHO [3] classified benzene as carcinogenic to humans, though no safe level of exposure is recommended yet. Synder [4] indicates that exposure in the range of 13.0 to $45.0 \mu \mathrm{g} / \mathrm{m} 3(4.07-14.11 \mathrm{ppm}$ ) could yield 1 cancer in 10,000 exposed people. Meanwhile, toluene, ethyl benzene and xylenes are also classified as potential carcinogens to humans [5].

The human exposure to benzene, toluene, ethyl benzene and xylenes were from inhalation of contaminated air either from naturally-occurring compounds in crude oil or from primary man-made sources into the environment such as through emissions from motor vehicles, aircraft exhaust, fuel filling stations and cigarette smoke [6]. Most benzene exposure for non-smoker is derived from vehicle exhaust or petrol vapour emissions [7]. WHO [3] stated that the exposure can occur either occupationally or domestically from continuous usage of petroleum products, including motor fuels and solvents. Increasing number of vehicles especially in urban area increase human exposure to BTEXs. Moreover, many sources of BTEXs such as fuel stations and workshops are located in urban area.

Indoor and outdoor exposure of BTEXs was correlated with specific sources. Several research $[8,9]$ have pointed out that BTEXs level in residential indoor air closed to a petrol filing station or an industrial areas are higher. Workers who are exposed directly to BTEX from a specific source will face health risks [10-12]. Therefore, health risk assessment is important to evaluate the hazards and adverse impacts of pollutants such as BTEXs to human health [13]. Determination of gases in ambient air required specific techniques for sampling and analysis. Application of Tedlar® bag for whole air sampling was an established sampling method i.e. EPA TO-15. Similarly, direct analysis of BTEX in Thermal Desorption (TD) coupled with Gas Chromatography Mass Spectrometer (GCMS) is a standard procedure as well. This procedure is easy, rapid and green since no solvent is involved in the extraction [14].

In this study, concentrations of BTEXs in several indoor and outdoor locations were measured and their possible sources were identified. Estimation of health risk related to benzene exposure was calculated and compared with other related studies.

\section{Material and Method}

\subsection{Sampling}

A total of 11 sampling sites were selected in areas of Serdang, Selangor. Among the samples, three indoor locations belong to automobile and motorcycle repair shops; three in the vicinity of petroleum fuel refill stations; one from roadside, one at the faculty and one at a residential hostel (Universiti Putra Malaysia). The sampling period was August- September 2015. 


\subsection{Sampling method}

Personal Air Sampler (PAS, Supelco) was set at $100 \mathrm{ml} / \mathrm{min}$ flowrate. The pump was calibrated using Air Flow Calibrator (Go Cal, Sensidyne). 1L of Tedlar bag (Supelco) was used to collect the air. With approximately 8-10 minutes of sampling time $800-1000 \mathrm{ml}$ of air could be collected. From this $500 \mathrm{ml}$ of air was pumped through the TD system for the BTEXs analysis.

\subsection{Analysis with TD-GCMS}

Air samples were directly pumped using the automated controller (CIA Advantage, Markes) onto the TD System (Unity, Markes). The system was equipped with a cool, Air Toxic Analyser Trap U-T15ATA-2S (Markes, UK) to concentrate the BTEXs before further desorption to the GC-MS system.

Separation of gases (BTEXs) was done using a gas chromatography Agilent 6890N (Agilent, USA) and detected by Agilent 5975C (Agilent, USA) Mass Selective Detector. DB-624 (J\&W Scientific, USA) capillary column (60 m length, $0.32 \mathrm{~mm}$ i.d, $1.80 \mu \mathrm{m}$ film thickness) was used for the separation. Parameters setting for TD and GCMS are shown in Table 1.

\begin{tabular}{|c|c|}
\hline \multicolumn{2}{|l|}{ Desorption parameters } \\
\hline Desorption temperature & $280^{\circ} \mathrm{C}$ for $\mathrm{VOCs}$ \\
\hline Desorption time & $30 \mathrm{~min}$ for VOCs \\
\hline Split flow & Splitless \\
\hline Flow path temperature & $150^{\circ} \mathrm{C}$ \\
\hline Line-purge & $1 \mathrm{~min}$ \\
\hline Trap-purge & $3 \min$ \\
\hline Sampling valve & $0.5 \mathrm{~L}$ \\
\hline \multicolumn{2}{|l|}{ GC-MS parameters } \\
\hline Temperature program & Initial $40^{\circ} \mathrm{C}(4 \mathrm{~min}), 4^{\circ} \mathrm{C} / \mathrm{min}$ to $220^{\circ} \mathrm{C}(2 \mathrm{~min})$ \\
\hline Inlet temperature & $200^{\circ} \mathrm{C}$ \\
\hline Auxiliary temperature & $280^{\circ} \mathrm{C}$ \\
\hline MS Quad & $150^{\circ} \mathrm{C}$ \\
\hline MS Source & $230^{\circ} \mathrm{C}$ \\
\hline Scan mass range & $35-300 \mathrm{amu}$ \\
\hline
\end{tabular}

Table 1: TD and GC-MS parameters.

\subsection{Quality Assurance/ Quality Control}

Multiple points calibration was performed in order to create quantification curve for BTEXs. Gas standard $10 \mathrm{ppm}$ (MESA, USA) was diluted proportionally with purified air in pre-clean $10 \mathrm{~L}$ Tedlar ${ }^{\circledR}$ bag for the calibration purposed. Limit of detection (LOD) was calculated based on 3 standard deviation of the lowest calibration (1 ppb). Good correlation was observed for all compounds as shown in Table 2. 


\begin{tabular}{|l|l|c|c|}
\hline $\begin{array}{l}\text { Compound } \\
\text { Name }\end{array}$ & \multicolumn{1}{|c|}{ Formula } & $\begin{array}{c}\text { Correlation } \\
\text { coefficient } \mathbf{R}_{\mathbf{2}}\end{array}$ & $\begin{array}{c}\text { LOD } \\
\text { (ppb) }\end{array}$ \\
\hline Benzene & $\mathrm{y}=3 \mathrm{E}+06 \mathrm{x}-4 \mathrm{E}+06$ & 0.9975 & 0.08 \\
\hline Toluene & $\mathrm{y}=2 \mathrm{E}+06 \mathrm{x}+6 \mathrm{E}+06$ & 0.9979 & 0.07 \\
\hline Ethylbenzene & $\mathrm{y}=2 \mathrm{E}+06 \mathrm{x}+2 \mathrm{E}+06$ & 0.9959 & 0.02 \\
\hline m,p-Xylene & $\mathrm{y}=3 \mathrm{E}+06 \mathrm{x}+7 \mathrm{E}+06$ & 0.9920 & 0.02 \\
\hline o-Xylene & $\mathrm{y}=1 \mathrm{E}+06 \mathrm{x}+2 \mathrm{E}+06$ & 0.9917 & 0.02 \\
\hline
\end{tabular}

Table 2: QA/QC studies on BTEX measurements.

\section{Results and Discussion}

\subsection{BTEXs level}

3.1.1 Indoor air: Concentration of individual component of BTEXs in indoor and outdoor samples was quantified (Table 3). The highest $\Sigma$ BTEXs concentration for indoor air was found in ID1 $\left(864.29 \mu \mathrm{g} / \mathrm{m}^{3}\right)$, followed by ID3 $\left(655.79 \mu \mathrm{g} / \mathrm{m}^{3}\right)$, ID2 $\left(115.32 \mu \mathrm{g} / \mathrm{m}^{3}\right)$, ID5 $\left(96.05 \mu \mathrm{g} / \mathrm{m}^{3}\right)$ respectively and the lowest was in ID4 $\left(72.99 \mu \mathrm{g} / \mathrm{m}^{3}\right)$. The highest concentration in ID1 and ID2 revealed that motorcycle workshops with gasoline vapours are a principle source of BTEXs. Many researchers have found out that motorcycles especially with two-stroke engines produced more VOCs from incomplete burning of fuel in the engines $[15,16]$. Car workshop A (ID3) was also detected with high concentration of BTEXs in comparison to sites ID4 and ID5. Toluene was the most abundant compound in all sites except ID5. Toluene/benzene (T/B) ratio for all indoor sites (1.58-2.20) indicated that gasoline fuel was the principle emission source. Ratio of T/B was always used as an indicator of vehicular emission [16, 17] and according to a study by Lan and Binh, T/B ratio of 2 indicated mainly a vehicular emission from petrol fuel in Malaysia.

\begin{tabular}{|c|c|c|c|c|c|c|c|}
\hline & \multirow[t]{2}{*}{ Sample Description } & Benzene & Toluene & $\begin{array}{c}\text { Ethyl } \\
\text { Benzene }\end{array}$ & $\begin{array}{c}\text { m,p- } \\
\text { Xylene }\end{array}$ & o-xylene & $\Sigma$ BTEXs \\
\hline & & \multicolumn{6}{|c|}{ Concentration $\left(\mu \mathrm{g} / \mathrm{m}^{3}\right)$} \\
\hline \multicolumn{8}{|l|}{ Indoor } \\
\hline ID $1^{*}$ & Motorcycle workshop A & 153.56 & 332.21 & 111.83 & 122.88 & 143.81 & 864.29 \\
\hline ID 2 & Motorcycle workshop B & 25.12 & 57.69 & 5.47 & 11.94 & 15.10 & 115.32 \\
\hline ID 3* & Car workshop A & 98.62 & 191.79 & 109.63 & 120.20 & 135.55 & 655.79 \\
\hline ID 4 & Car workshop B & 12.17 & 25.31 & 5.09 & 11.09 & 19.33 & 72.99 \\
\hline
\end{tabular}




\begin{tabular}{|c|c|c|c|c|c|c|c|}
\hline ID 5 & Car workshop C & 12.55 & 19.90 & 9.24 & 23.65 & 30.71 & 96.05 \\
\hline \multicolumn{8}{|l|}{ Outdoor } \\
\hline OD 1* & Petrol station A & 48.77 & 101.79 & 57.92 & 70.34 & 88.63 & 367.45 \\
\hline OD 2 & Petrol station B & 19.15 & 37.69 & 3.15 & 8.50 & 16.63 & 85.12 \\
\hline OD 3 & Petrol station $\mathrm{C}$ & 9.9 & 19.91 & 3.95 & 3.29 & 13.24 & 50.29 \\
\hline OD 6 & Roadside, UPM & 7.79 & 33.81 & 31.00 & 28.25 & 59.09 & 159.94 \\
\hline OD 7 & $\begin{array}{l}\text { Faculty of Environmental Studies, } \\
\text { UPM }\end{array}$ & 7.45 & 32.51 & 0.58 & 0.67 & 4.81 & 46.02 \\
\hline OD 8 & Residence College, UPM & 5.44 & 51.63 & 1.41 & 3.10 & 6.99 & 68.57 \\
\hline
\end{tabular}

*Collected close to the fuel source.

Table 3: BTEXs concentration $\left(\mu \mathrm{g} / \mathrm{m}^{3}\right)$ in indoor and outdoor samples.

3.1.2 Outdoor air: Among the outdoor samples collected, OD1 was detected with the highest $\Sigma$ BTEXs (367.45 $\left.\mu \mathrm{g} / \mathrm{m}^{3}\right)$, followed by OD6 $\left(159.94 \mu \mathrm{g} / \mathrm{m}^{3}\right)$, OD2 $(85.12 \mu \mathrm{g} / \mathrm{m})$, OD8 $\left(68.57 \mu \mathrm{g} / \mathrm{m}^{3}\right)$, OD3 $\left(50.29 \mu \mathrm{g} / \mathrm{m}^{3}\right)$, and OD7 $\left(46.02 \mu \mathrm{g} / \mathrm{m}^{3}\right)$ respectively. Toluene was found the most abundant compound in all samples except in the case of OD6 where o-Xylene was the highest. T/B ratio for outdoor samples (OD1-OD3) revealed a ratio of 2 indicating gasoline as a source. A ratio of 2.2 was also observed by Lan [16] in roadside ambient air of Kuala Lumpur. High T/B ratio of >4-10 for outdoor samples (OD6-OD8) indicates additional sources such as industrial emission in those areas.

Benzene level in outdoor samples was found high in all petrol stations sites (OD1>OD2>OD3), followed by OD6 (roadside), OD7 (Faculty) and OD8 (Residential). The result clearly indicated outdoor benzene risk in the following order petrol stations $>$ roadside $>$ faculty $>$ residential area.

3.1.3 Benzene health assessment: Health risk estimation for benzene in indoor and outdoor sites was based on Lifetime Average Daily Doses (LADD), cancer risk (CR) and hazard quotient (HQ). Calculation of LADD, CR and HQ for indoor and outdoor samples was based on Edokpolo et al. [18]. All parameters for the calculation were based on United State Environment Protection Agency (US EPA) recommendation value. According to the US EPA, a cancer risk above $1 \times 10^{-6}$ is critical, as it significantly increases carcinogenic potential in humans. A hazard quotient (HQ) is a measure of potential overall hazard risk. A HQ of $\geq 1$ is considered as an "adverse noncarcinogenic effect of concern"; while a value of $\leq 1$ is within acceptable limit. 


\begin{tabular}{|c|c|c|c|}
\hline Sample & $\begin{array}{c}\text { LADD } \\
(\mu \mathrm{g} / \mathrm{kg} / \mathrm{d})\end{array}$ & $\begin{array}{c}\text { Cancer Risk } \\
\text { (CR) }\end{array}$ & $\begin{array}{c}\text { Hazard Quotient } \\
\text { (HQ) }\end{array}$ \\
\hline \multicolumn{4}{|l|}{ Indoor } \\
\hline ID 1 & 3.42 & $9.34 \times 10^{-5}$ & 0.40 \\
\hline ID 2 & 0.56 & $1.53 \times 10^{-5}$ & 0.07 \\
\hline ID 3 & 2.20 & $6.00 \times 10^{-5}$ & 0.26 \\
\hline ID 4 & 0.27 & $7.40 \times 10^{-6}$ & 0.03 \\
\hline ID 5 & 0.28 & $7.63 \times 10^{-6}$ & 0.03 \\
\hline \multicolumn{4}{|l|}{ Outdoor } \\
\hline OD 1 & 1.88 & $5.15 \times 10^{-5}$ & 0.22 \\
\hline OD 2 & 0.74 & $2.02 \times 10^{-5}$ & 0.09 \\
\hline OD 3 & 0.38 & $1.05 \times 10^{-5}$ & 0.04 \\
\hline OD 4 & 0.23 & $6.23 \times 10^{-6}$ & 0.03 \\
\hline OD 5 & 0.22 & $5.96 \times 10^{-6}$ & 0.03 \\
\hline OD 6 & 0.16 & $4.35 \times 10^{-6}$ & 0.02 \\
\hline
\end{tabular}

Table 4: Calculated benzene health risk.

Table 4 shows the results of calculated LADD, CR and HQ for indoor (ID1-ID5) and outdoor (OD1-OD6) air samples. Indoor samples for ID1 showed the highest LADD $(3.42 \mu \mathrm{g} / \mathrm{kg} / \mathrm{d})$, followed by ID3 (2.20 $\mu \mathrm{g} / \mathrm{kg} / \mathrm{d})$, ID2 $(0.56 \mu \mathrm{g} / \mathrm{kg} / \mathrm{d})$, ID5 $(0.28 \mu \mathrm{g} / \mathrm{kg} / \mathrm{d})$ and ID4 $(0.27 \mu \mathrm{g} / \mathrm{kg} / \mathrm{d})$. All samples from indoor air exceeded the cancer risk guideline $\left(>1 \times 10^{-6}\right)$ indicating cancer risk to workers. ID1 and ID3 are air samples collected from motorcycle and car workshops with one of the highest risk value of $9.34 \times 10^{-5}$ and $6.00 \times 10^{-5}$ respectively. However, HQ results $(<1)$ from all indoor samples represent less effect of non-cancer risk to the workers based on benzene level.

CR value for all outdoor samples were also higher than the recommended limit. Petrol stations (OD1-OD3) were calculated with a value of $5.15 \times 10^{-5}, 2.02 \times 10^{-5}$ and $1.05 \times 10^{-5}$ respectively. However, the results were lower than in a study by Moolla et al. [12] in a diesel station bus depot. Meanwhile, OD4-OD7 indicated CR value of $6.23 \times 10^{-6}$, $5.96 \times 10^{-6}$ and $4.35 \times 10^{-6}$ respectively. Benzene cancer risk results in ambient roadside, faculty and residential area were also high if one considers the study of Garg et al. [19] in India. The CR results for outdoor samples suggest that all samples close to fossil fuel or vehicles were at cancer risk. HQ results for outdoors samples with <1 suggested non-cancer risk of benzene in all sampling sites.

\section{Conclusion}

In summary, BTEX was prevalent in both indoor and outdoor samples in Serdang, Malaysia. The highest concentrations were recorded always at sites close to petroleum products e.g. petrol stations, automobile workshops. The toluene/benzene ratios confirm this finding. Staggeringly, health risk calculations based on LADD, CR and HQ indicate that Malaysians are at risk both in indoor and outdoor from benzene exposure. The current results suggest for more intense sampling throughout urban environment in Malaysia for risk assessment with BTEX pollution. 


\section{References}

1. Campos-Candel A, Llobat-Estellés M, Mauri-Aucejo AR. Desorption of BTEX from activated charcoal using accelerated solvent extraction: evaluation of occupational exposures. Analytical and bioanalytical chemistry 387 (2007): 1517-1523.

2. Asante-Duah DK. Hazardous Waste Risk Assessment, Lewis Publishers, FL, USA (1993).

3. WHO Benzene. In: Air quality guidelines for Europe, 2nd ed. Copenhagen, World Health Organization Regional Office for Europe (2000).

4. Snyder R. Leukemia and Benzene. International Journal of Environmental Research and Public Health 9 (2012): 2875-2893.

5. Słomińska M, Konieczka P, Namieśnik J. The Fate of BTEX Compounds in Ambient Air. Critical Reviews in Environmental Science and Technology 44 (2014): 455-472.

6. Leusch F, Bartkow M. A short primer on benzene, toluene, ethylbenzene and xylenes (BTEX) in the environment and in hydraulic fracturing fluids (2010).

7. Wallace L. Environmental exposure to benzene: an update. Environmental Health Perspective 104 (1996): 1129-1136.

8. Godoi RHM, Godoi AFL, Gonçalves SJ, et al. Healthy environment- indoor air quality of Brazilian elementary schools nearby petrochemical industry. Science of The Total Environment 463 (2013): 639646.

9. Gennaro G, Di Dambruoso PR. Gilio A, Di Marzocca A, Tutino, M. Indoor and outdoor volatile organic compounds monitoring in a multi-storey car park. Environmental Engineering and Management Journal 14 (2015): 1563-1570.

10. Bohlin, P, Jones KC, Strandberg B. Occupational and indoor air exposure to persistent organic pollutants: a review of passive sampling techniques and needs. Journal of Environmental Monitoring 9 (2007): 501-509.

11. Tunsaringkarn T, Prueksasit T, Kitwattanavong M, et al. Cancer risk analysis of benzene, formaldehyde and acetaldehyde on gasoline station workers. journal of Environmental Engineering and Ecological Science (2012).

12. Moolla R, Curtis CJ, Knight J. Occupational exposure of diesel station workers to BTEX compounds at a bus depot. International Journal of Environmental Research and Public Health 12 (2015): 4101-4015.

13. Zhang Y, Mu Y, Liu J, et al. Levels, sources and health risks of carbonyls and BTEX in the ambient air of Beijing, China. Journal of Environmental Sciences 24 (2012): 124-130.

14. Woolfenden E. Monitoring VOCs in Air Using Sorbent Tubes Followed by Thermal Desorption-Capillary GC Analysis: Summary of Data and Practical Guidelines. Journal of the Air \& Waste Management Association 47 (2011): 20-36.

15. Chang CT, Chen BY. Toxicity assessment of volatile organic compounds and polycyclic aromatic hydrocarbons in motorcycle exhaust. Journal of Hazardous Materials 153 (2008): 1262-1269.

16. Lan TTN, Binh NTT. Daily roadside BTEX concentrations in East Asia measured by the Lanwatsu, Radiello and Ultra I SKS passive samplers. The Science of the Total Environment 441 (2012): 248-257. 
17. Khoder MI. Ambient levels of volatile organic compounds in the atmosphere of Greater Cairo. Atmospheric Environment 41 (2007): 554-566.

18. Edokpolo B, Yu QJ, Connell D. Health Risk Assessment of Ambient Air Concentrations of Benzene, Toluene and Xylene (BTX) in Service Station Environments. International Journal of Environmental Research and Public Health 11 (2014): 6354-6374.

19. Garg A, Sushil KT, Prodyut B. Risk assessment of benzene in ambient. International Journal of Current Research 8 (2016): 37532-37538.

(C) (7) This article is an open access article distributed under the terms and conditions of the Creative BY Commons Attribution (CC-BY) license 4.0 